\title{
Measurements of Electromagnetic Noise and Cosmic Radiation Doses in an Aircraft
}

\author{
Shun-ichi Himeno, Takayasu TANaka and Masaharu Sekr* \\ Nippon Bunri University \\ 1727 Ichigi, Oita-shi 870-0397, Japan \\ ${ }^{*}$ Hokkaido Information University \\ 59-2 Nishi Nopporo, Ebetsu-shi Hokkaido 069-0832, Japan
}

Received December 27, 1999

\begin{abstract}
Electromagnetic noise from radiation detectors and from an aircraft itself were examined using a field meter. It was proved that the electromagnetic noise from radiation detectors is smaller than that from the aircraft.

Dose equivalent rates due to cosmic ray neutrons and ionizing radiation were measured using $a$ moderated ${ }^{3} \mathrm{He}$ counter and a $\mathrm{CsI}(\mathrm{Tl})$ scintillation counter in a commercial aircraft at an altitude of approximately $10 \mathrm{~km}$, between Narita, Japan and Vancouver, Canada. The measured data were compared with the results calculated using calculation code (CARI-2), and it was found that both agree approximately.
\end{abstract}

Key Words: electromagnetic noise, electromagnetic field meter, aircraft, cosmic radiation dose, tritium counter, $\mathrm{CsI}(\mathrm{Tl})$ counter

\section{Introduction}

Cosmic radiation interacts with the atmosphere and produces secondary radiation consisting of ionizing components and neutrons. Both components contribute to the radiation encountered at aircraft flight altitudes ${ }^{1)}$ and the intensities vary with altitude and geomagnetic latitude ${ }^{2}$. Recently, the exposure to cosmic rays in aircraft has become of wide interest, however the effect of detector noise and aircraft noise on aircraft electronics has not been published to date.

In this study, various kinds of detector noise and aircraft noise are first examined. The dose equivalent rates of neutrons and ionizing components of cosmic rays according to altitude and geomagnetic latitude are also measured. In situ measured data was compared with values obtained from CARI-2 code developed by Friedberg et al. ${ }^{1)}$.

\section{Electromagnetic Noise from Radia- tion Detectors and Aircraft}

Before the airborne experiment was undertaken, instrument noise from the various radiation detectors was measured using a field meter (TriField Meter, W.B. Lee), which was able to measure the low frequency electric field, magnetic field, and radio/microwave field. The lower detection limits were about $0.1 \mathrm{kV} / \mathrm{m}, 0.1 \mathrm{mG}$, and $0.01 \mathrm{~mW} / \mathrm{cm}^{2}$, respectively. Electric noise $(\mathrm{kV} /$ $\mathrm{m})$ is shown in Fig. 1. The closed triangles $(\boldsymbol{\Delta})$ represent noise from a gamma spectrometer (Aloka), closed squares ( $\square$ ); GM counter (Shimadzu), open triangles $(\nabla) ;{ }^{3} \mathrm{He}$ neutron survey meter (Aloka), open circles $(\bigcirc)$; $\mathrm{CsI}(\mathrm{Tl})$ scintillation survey meter called "Hakarukun" (Horiba), and closed circle (O); digital wristwatch. No electric 


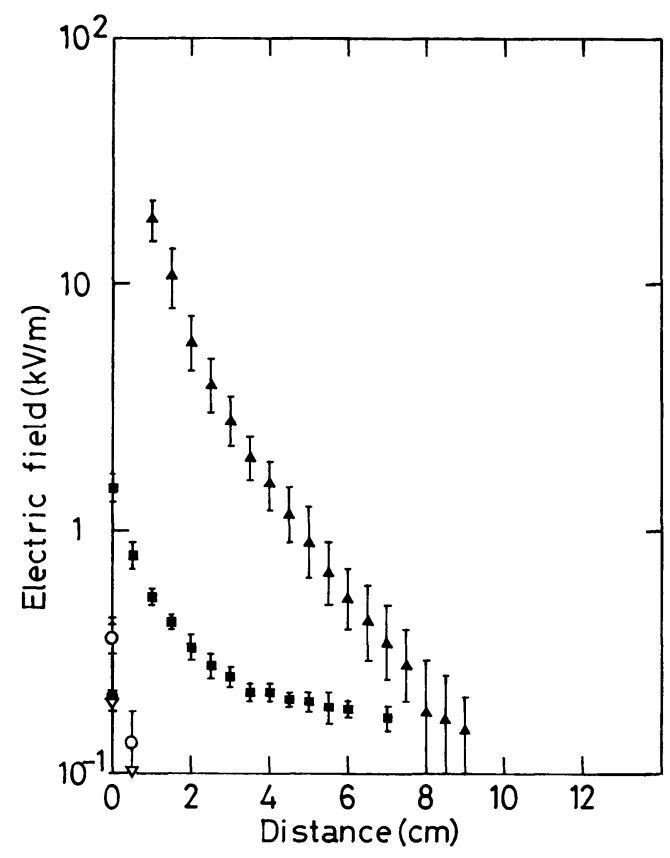

Fig. 1 Electric noise versus distance from various detectors on the ground measured using the TriField Meter (W.B. Lee). $\boldsymbol{\Delta}:$ gamma spectrometer (Aloka),
$\mathbf{\square}$ : GM counter (Shimadzu), $\nabla:$ neutron survey meter (Aloka), $\bigcirc$ : handy-type radiation survey meter "Hakarukun" (Horiba), : wristwatch. (Magnetic and radio/microwave noises from neutron survey meter and "Hakarukun" were not detected).

field was detected more than $10 \mathrm{~mm}$ away from either Hakarukun or the neutron survey meter, and neither a magnetic field nor a radio/microwave field was detected on the surface of Hakarukun or the neutron survey meter using this field meter. The frequency spectrum of Hakarukun and the ${ }^{3} \mathrm{He}$ counter were seperately analyzed with a Spectrum Display Unit (SD5500, AOR), however, no significant noise was observed in the frequency band of aeronautical radio.

The time variation of magnetic noise $(\mathrm{mG})$ (accuracy: $\pm 20 \%$ ) measured at a window seat in

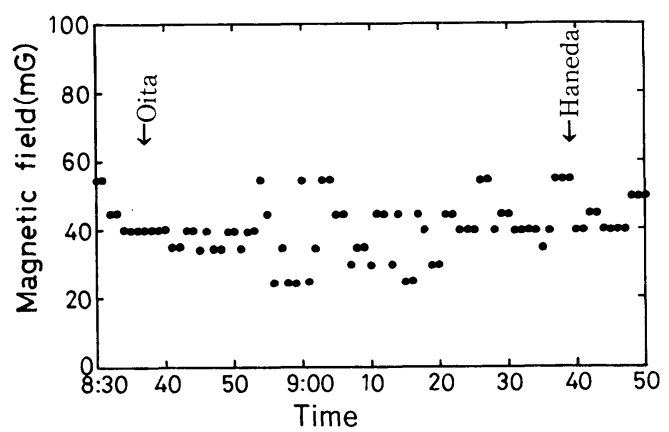

Fig. 2 Time variation of magnetic noise at window seat in middle of aircraft measured using TriField Meter, from Oita to Haneda with the radiation detector switched on (Magnetic noise from detectors was not detected.).

the middle of the aircraft using the field meter, from Oita to Haneda with the radiation detector switched on is shown in Fig. 2. Electric and radio/microwave noise in the aircraft were below the lower limits of measurement of this particular field meter. The electric field on the surface of a CRT television screen in the aircraft was between 15 and $20 \mathrm{kV} / \mathrm{m}$ (which is about 50 times that from Hakarukun) and the magnetic field was between 20 and $60 \mathrm{mG}$ (which is much greater than that from Hakarukun, and nearly equal to that from the engines). If we assume that magnetic detector noise and engine noise are $0.1 \mathrm{mG}$ (which is less than the geomagnetic field) and 40 $\mathrm{mG}$, respectively, then the ratio of the former to the latter is $1 / 400$. Some analogue wristwatches generate magnetic fields of a few milligauss. From these results and the fact that electric and magnetic fields decrease in inverse proportional to the square of the distance between the source and the detector ${ }^{3)}$, instrument noises from the neutron survey meter and the handy-type radiation survey meter are not considered to affect the electronics of the aircraft which is more than few meters away from the radiation detector. 
3. Flight Path of the Airborne Experiment

The radiation dose data reported here was obtained on flights between Narita (geographic latitude $35^{\circ} \mathrm{N}$, longitude $140^{\circ} \mathrm{E}$; geomagnetic latitude about $26^{\circ} \mathrm{N}$ ) and Vancouver (geographic latitude $45^{\circ} \mathrm{N}$, longitude $123^{\circ} \mathrm{W}$; geomagnetic latitude about $\left.55^{\circ} \mathrm{N}\right)$. The flight path is indicated by a solid line in Fig. 3. Geographic latitudes and longitudes are also shown.

\section{Instrumentation}

The dose equivalent rates of neutrons and ionizing particles were maesured using amoderated ${ }^{3} \mathrm{He}$ neutron survey meter (counter) and a CsI(Tl) handy-type scintillation survey meter Hakarukun, respectively. The ${ }^{3} \mathrm{He}$ neutron survey meter has a dose rate sensitivity of $10^{-2} \mu \mathrm{Sv} / \mathrm{h}$. Data from the ${ }^{3} \mathrm{He}$ survey meter and the CsI(Tl) survey meter are renewed about every one minute and every ten seconds, respectively.

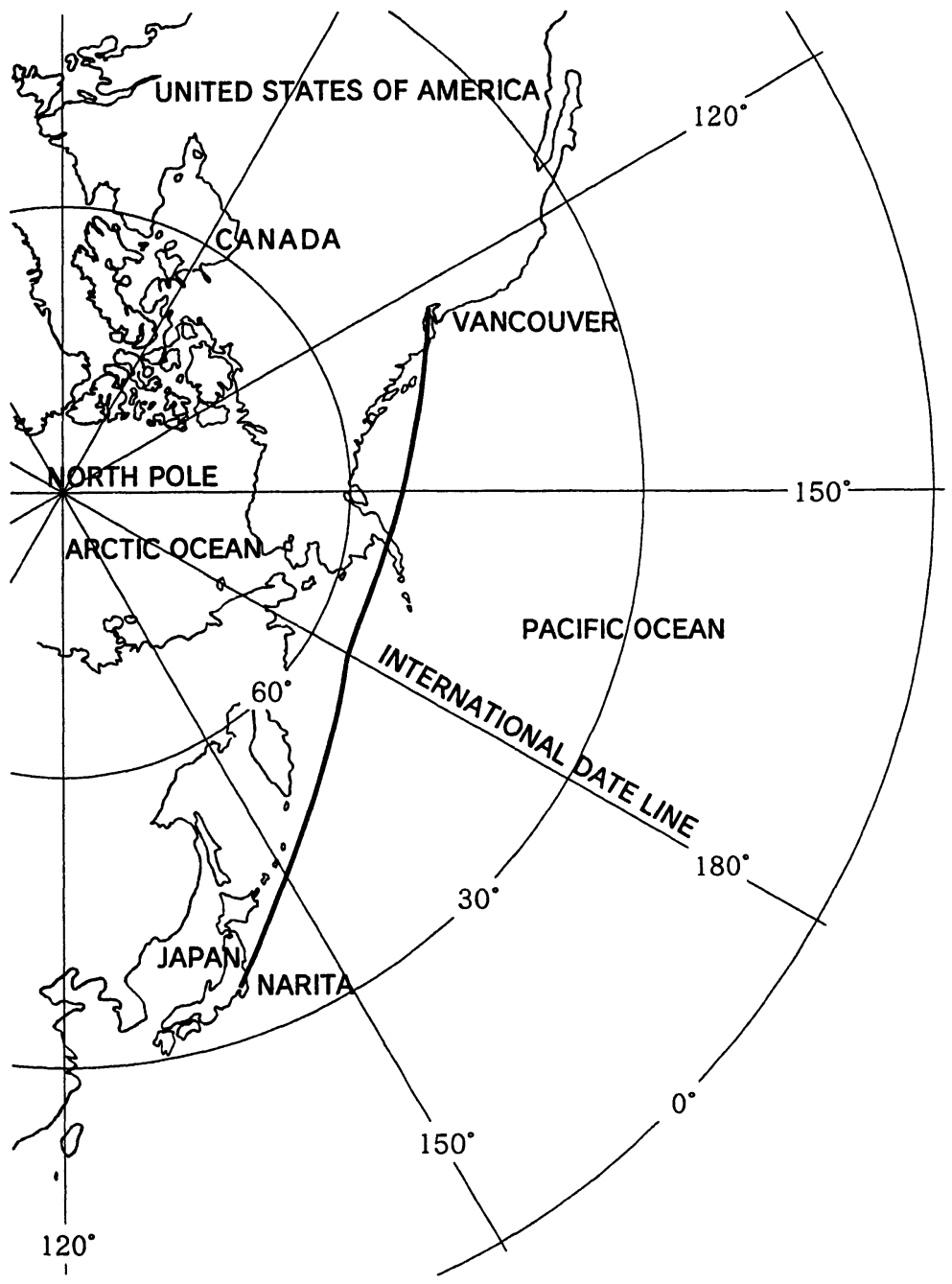

Fig. 3 The flight path from Narita to Vancouver for measuring cosmic radiation doses. Geographic latitudes and longitudes are represented by solid lines. 


\section{Results and Discussion for Airborne Experiment}

The dose equivalent rates of neutrons, as measured with the ${ }^{3} \mathrm{He}$ neutron surveymeter, as a function of Japan Standard Time (JST) during a flight from Narita to Vancouver (on Apr. 18, 1998) are shown in Fig. 4(a). The open circle ( $\bigcirc)$ represents the calculated dose rate at the international date line, as obtained using CARI-2 code developed by Freidberg et al. ${ }^{1)}$.

The dose equivalent rate of ionizing particles as measured with the CsI(T1) scintillation counter is shown in Fig. 4(b). The measured values are multiplied by 12 according to Okano's paper ${ }^{4}$. Again, the open circle represents the calculated value using CARI-2 code. In this figure, the dose equivalent rate first decreases as aircraft altitude increases up to the cloud level as a result of the decrease of the effect of the Earth's radiation. The dose equivalent rate then increases up to cruising altitude during further ascent due to cosmic rays. The maximum altitude was about $10 \mathrm{~km}$. Consis-

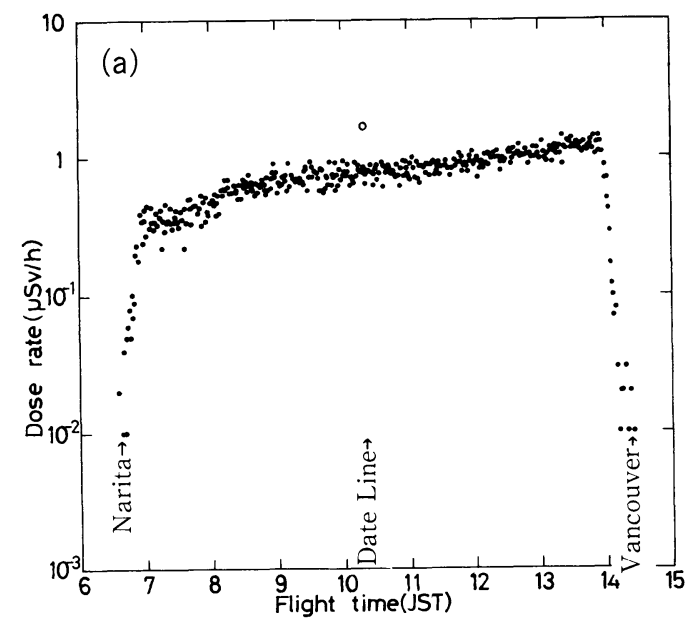

tent behavior is observed on decent.

The dose equivalent rates of neutrons and ionizing particles from Vancouver to Narita, respectively, are shown in Fig. 5(a) and 5(b) (on Apr. 25, 1998). The maximum altitude was about 11 $\mathrm{km}$. The open circles represent the calculated value using CARI-2 code. The most notable feature from Figs. 4 and 5 is that the dose rate increases with geomagnetic latitude. The average of the measured dose rate of neutrons and ionizing particles in Figs. 4(a) and 4(b) or 5(a) and 5(b) agrees approximately with the values calculated by CARI-2 code $^{5)}$.

A comparison between the integrated and calculated doses ( $\square$ ) obtained by CARI-2 code from Narita to Vancouver and from Vancouver to Narita is shown in Fig. 6. A heliocentric potential of $400 \mathrm{MV}$, which accounts for solar activity in 1998, was used. Integrated doses from east to west are higher than those from west to east because of the longer flight time and higher altitude. The average of the measured dose of neutrons and ionizing particles agrees approximately with the

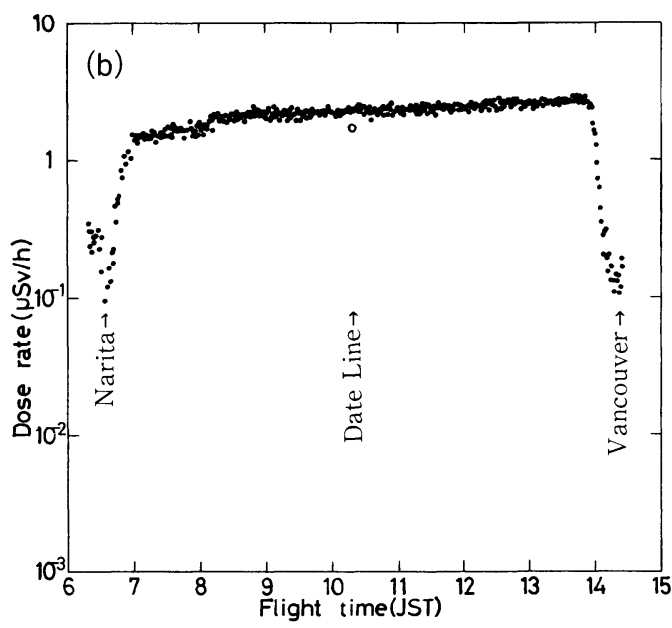

Fig. 4 (a) Time variation of dose equivalent rate measured using ${ }^{3} \mathrm{He}$ counter in flight from Narita to Vancouver.

(b) Time variation of dose equivalent rate measured using CsI(T1) scintillation counter "Hakarukun" in flight from Narita to Vancouver.

० : Dose rate calculated by CARI-2 code at date line. 

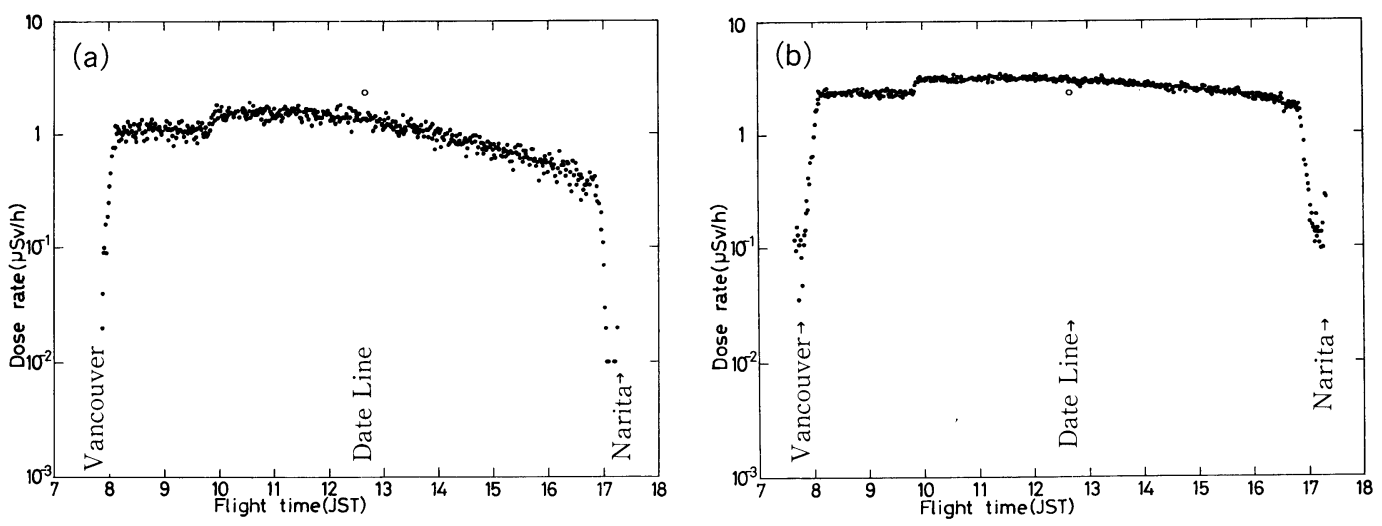

Fig. 5 (a) Time variation of dose equivalent rate measured using

${ }^{3} \mathrm{He}$ counter in flight from Vancouver to Narita.

(b) Time variation of dose equivalent rate measured using CsI(Tl) scintillation counter "Hakarukun" in flight from Vancouver to Narita.

o : Dose rate calculated by CARI-2 code at date line.

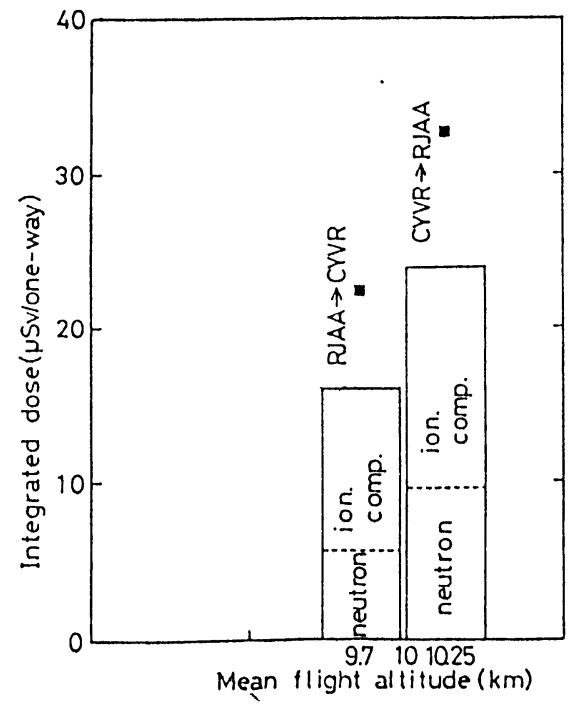

Fig. 6 Integrated doses in opposite flight direction measured on flights from/ to Narita.

RJAA : Narita, CYVR : Vancouver.

$\square$ : Doses calculated by CARI-2 code. H. P. $=400 \mathrm{MV}$.

value calculated by CARI-2 code.

The dose equivalent rates of neutrons and ionizing particles as a function of altitude as obtained from Figs. 4(a) and 4(b), assuming that the altitude changes linearly with time during ascent, are shown in Figs. 7(a) and 7(b). It is clear from
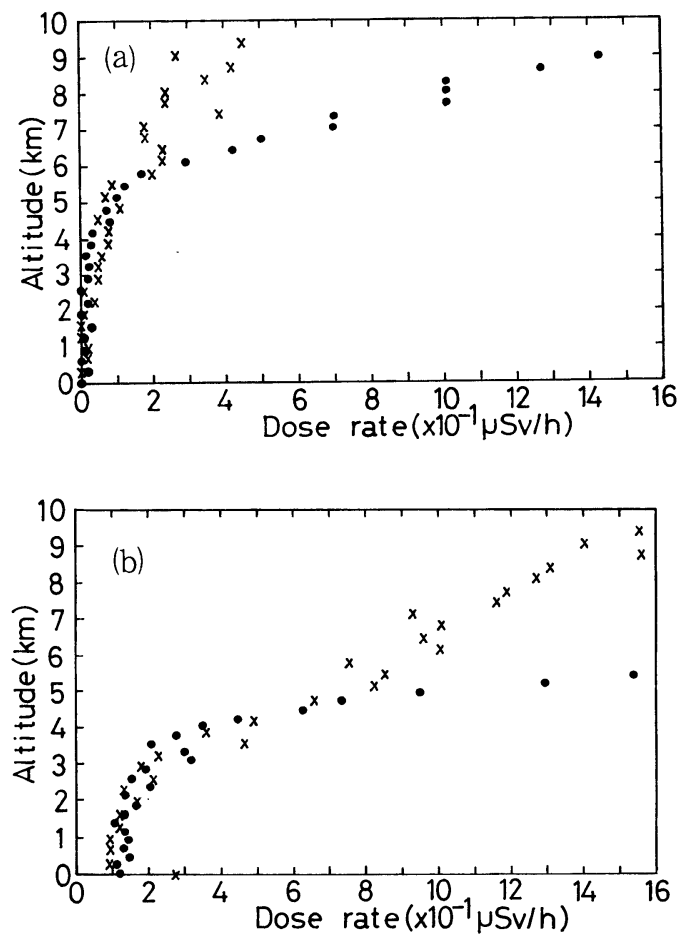

Fig. 7 (a) Altitude variation of dose equivalent rate of neutrons obtained from Fig. 4(a), assuming that altitude is proportional to flight time.

(b) Altitude variation of dose equivalent rate of ionizing particles obtained from Fig. 4 (b).

$\times:$ Narita, $\bullet:$ Vancouver. 
these figures that the dose rate near Vancouver increases more rapidly with altitude than that near Narita. This can be considered to be a result of the fact that the vertical component of the geomagnetic field near Vancouver is larger than that near Narita.

An explanation of this situation is provided in Fig. 8. The closed circle ( $)$ represents the vertical component of the geomagnetic field and the closed triangle $(\boldsymbol{\Delta})$ represents the horizontal component of the geomagnetic field, as a function of flight time (JST). The closed square ( $\square$ ) represents the vertical component of the geomagnetic field as calculated from the well-known dipole magnetic field equation ${ }^{6}$

$$
B_{\mathrm{r}}=2 M \cos \theta / 4 \pi \boldsymbol{r}^{3}
$$

where $M$ is the dipole moment and $\theta$ is the angle between the earth's radial vector $\boldsymbol{r}$ and the dipole moment. Geomagnetic latitude versus flight time (JST) is shown by open circles $(\bigcirc)$. In this figure it should be noted that the flight time is not always proportional to the geomagnetic latitude, because the flight path is not always in the increasing direction of the vertical component of the geomagnetic field.

The dose equivalent rates of neutrons obtained from Figs. 4(a) and 5(a) are shown in Fig. 9(a). The horizontal error bars represent the errors due to positional uncertainty. The solid line represents the least squares fitting values of the dose equivalent rates $(\bigcirc)$ calculated using the expression ${ }^{\text {7) }}$

$$
H_{\mathrm{n}}=K_{\mathrm{n}}(1-\cos 2 \lambda)
$$

where $H_{\mathrm{n}}$ is the dose equivalent rate of neutrons, $K_{\mathrm{n}}$ is a constant of proportionality, and $\lambda$ is the geomagnetic latitude.

The dose equivalent rates of ionizing particles obtained from Figs. 4(b) and 5(b) are shown in Fig. 9(b). The solid line indicates the least squares fitting values of the dose equivalent $\operatorname{rates}(\bigcirc)$ calculated using the expression ${ }^{2)}$

$$
H_{\mathrm{c}}=K_{\mathrm{c}}\left(1-\cos ^{4} \lambda\right)
$$

where $H_{\mathrm{c}}$ is the dose equivalent rate of the ionizing particles, $K_{\mathrm{c}}$ is a constant of proportionality, and $\lambda$ is the geomagnetic latitude.

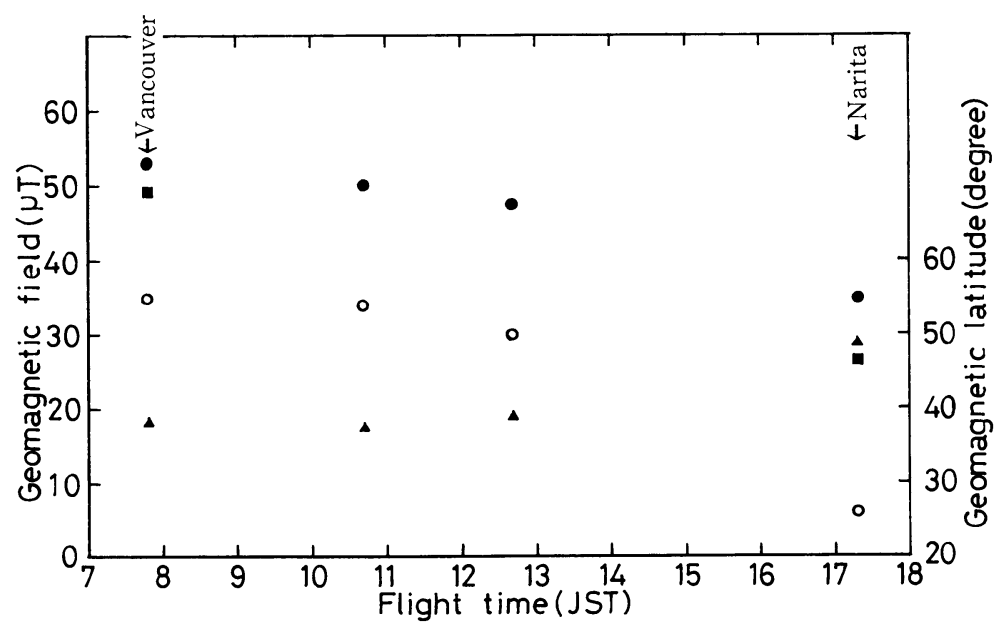

Fig. 8 Vertical component -1 and horizontal component $\boldsymbol{\Delta}$ of geomagnetic field versus flight time (JST).

Geomagnetic latitude $\bigcirc$ versus flight time (JST).

Vertical component of geomagnetic field $\mathbf{c}$ calculated using dipole momentum formula. 

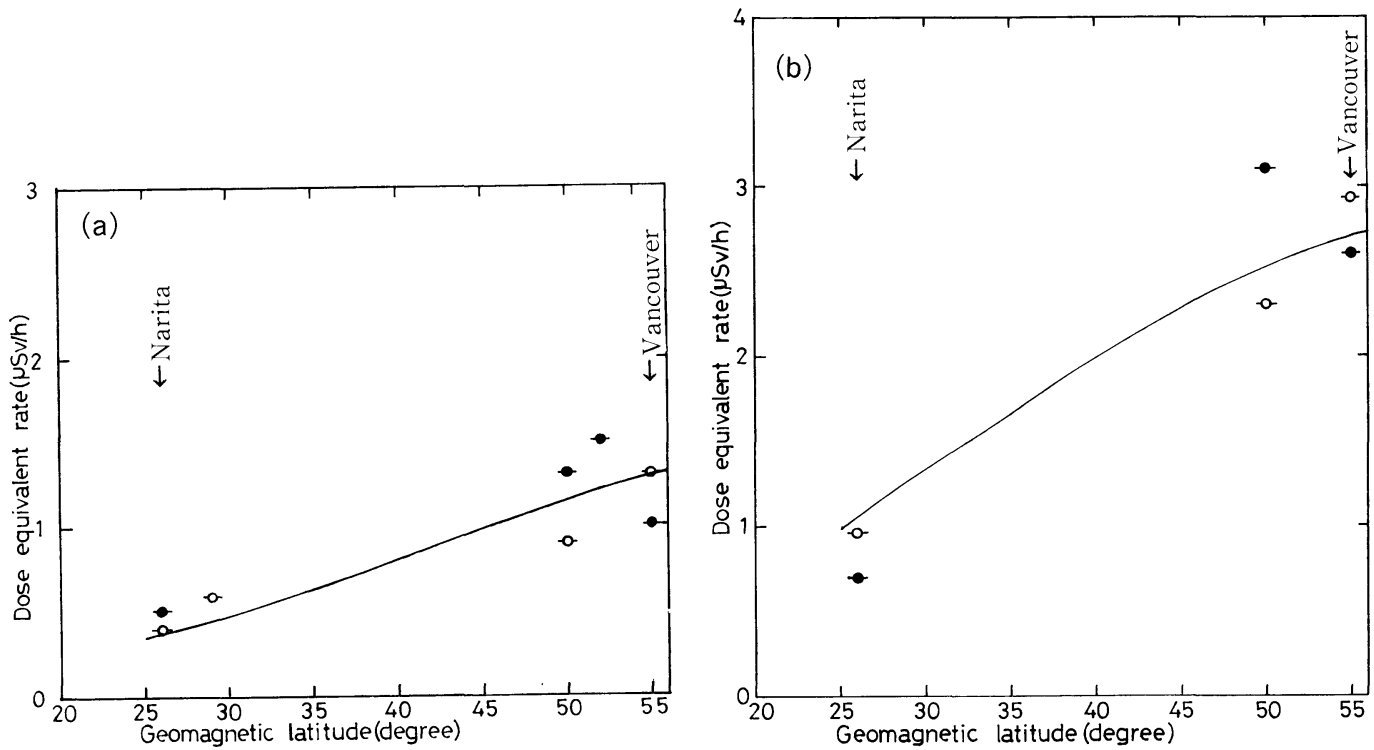

Fig. 9(a) Variation of dose equivalent rate of neutrons with geomagnetic latitude from Narita to Vancouver $\bigcirc$ and from Vancouver to Narita

(b) Variation of dose equivalent rate of ionizing particles with geomagnetic latitude from Naria to Vancouver $\bigcirc$ and from Vancouver to Narita

Horizontal error bars indicate the latitude uncertainty.

\section{Conclusion}

In this paper, instrument noise and the cosmic radiation doses to which aircraft passengers are subjected and calculations of cosmic radiation levels were discussed. Radiation detector noise can not be considered to affect the electronics of an aircraft, since it is negligibly small compared to aircraft noise itself. The neutron component of secondary cosmic rays is more sensitive to latitude changes than is the ionizing component. The dose equivalent rate in the aircraft is approximately 100 times as much as that at ground level around Vancouver.

\section{Acknowledgement}

The authors would like to thank Professor K. Noguchi of Nihon University and Dr. W. Friedberg of the Civil Aeromedical Institute for providing the CARI-2 code and for their helpful advice. Gratitude is also due to professor $\mathbf{H}$. Kunori, associate profesor $\mathrm{H}$. Katayama and other members of the Nippon Bunri University for their encouragement.

\section{References}

1) Fujitaka, K.:Hoken Butsuri, 31(4), 463-471 (1996) (in Japanese)

2) Kai, M., Dobashi, K. and Kusama, T. : ibid., 27, 289-294 (1992)

3) Akao, Y.: "Fundamentals of Electromagnetic Environment Engineering”, p. 115, Denshi-JohoTsushin-Gakkai (1991) (in Japanese) ; Takagi, T. et al. : "Biological Effects of Electromagnetic Fields and Measurement", p. 269, Corona Pulishing CO., LTD. (1995) (in Japanese)

4) Okano, M., Izumo, K. and Tendo, Y. : Hoshasen Eikyo Gakkai Yokoshu, p. 187 (1993) (in Japanese)

5) Friedberg, W. : Private communication (2000)

6) Ojima, M. ed. : "Introduction to Geophysics", p. 154, University of Tokyo (1990) (in Japanese)

7) Hewitt, J. E., Hughes, L., Baum, J. W., Kuehner, A. V., McCaslin, J. B., Rindi, A., Smith, A. R., Stephens, L. D., Thomas, R. H., Griffith, R. V. and Welles, C. G. : Health Phys., 34, 375-384 (1978) 
要 旨

\title{
航空機中の電磁ノイズおよび宇宙放射線の測定
}

\author{
姫野俊一，田中孝康，関 正治* \\ 日本文理大学工学部 \\ 870-0397 大分市一木 1727 \\ *北海道情報大学経営情報学部 \\ 069-0832 北海道江別市西野幌 59-2
}

放射線計測器および航空機自身からの電磁ノイズをフィールドメータを用いて調べた。前者は後 者よりあ小さいことが証明された。

次に, 成田からバンクーバ間の高度約 $10 \mathrm{~km}$ の民間航空機の宇宙線中の中性子と電離成分による 線量率をそれぞれ減速 ${ }^{3} \mathrm{He}$ カウンタおよび CsI(T1) シンチレーションカウンタを用いて測定した。 測定データは計算コード CARI-2による結果と比較され，両者はほとんど一致した。 